\title{
Metastatic Malignant Female Reproductive System Neoplasm
}

National Cancer Institute

\section{Source}

National Cancer Institute. Metastatic Malignant Female Reproductive System Neoplasm. NCI Thesaurus. Code C162254.

A malignant neoplasm that arises in the female reproductive system and has spread from its original site of growth to other anatomic sites. 